\title{
Psychological morbidity associated with prostate cancer: Rates and predictors of depression in the RADICAL PC study
}

Gagan Fervaha, MD, PhD ${ }^{1,2}$; Jason P. Izard, MD, MPH, FRCSC ${ }^{2,3}$; Dean A. Tripp, $\mathrm{PhD}^{2,4,5}$; Nazanin Aghel, MD ${ }^{6}$; Bobby Shayegan, MD, FRCSC ${ }^{7}$; Laurence Klotz, CM, MD, FRCSC ${ }^{8}$; Tamim Niazi, MD, FRCPC ${ }^{9}$; Vincent Fradet, MD, PhD, FRCSC ${ }^{10}$; Daniel Taussky, MD ${ }^{11}$; Luke T. Lavallée, MD, CM, MSc, FRCSC ${ }^{12}$; Robert J. Hamilton, MD, MPH, FRCSC ${ }^{13}$; Ian Brown, MD, FRCSC ${ }^{14}$; Joseph Chin, MD, FRCSC ${ }^{15}$; Darin Gopaul, MD, FRCSC ${ }^{16}$; Philippe D. Violette, MD, FRCSC ${ }^{17}$; Margot K. Davis, MD, MSc, FRCPC ${ }^{18}$; Sarah Karampatos, MSc ${ }^{19}$; Jehonathan H. Pinthus, MD, PhD, FRCSC ${ }^{7}$; Darryl P. Leong, MBBS, MPH, M.Biostat, PhD ${ }^{19,20}$; D. Robert Siemens, MD, FRCSC ${ }^{2,3}$; on behalf of the RADICAL PC Investigators

${ }^{1}$ School of Medicine, Faculty of Health Sciences, Queen's University, Kingston, ON, Canada; ${ }^{2}$ Department of Urology, Faculty of Health Sciences, Queen's University, Kingston, ON, Canada; ${ }^{3}$ Department of Oncology, Faculty of Health Sciences, Queen's University, Kingston, ON, Canada; ${ }^{4}$ Department of Psychology, Faculty of Arts and Sciences, Queen's University, Kingston, ON, Canada; ${ }^{5}$ Department of Anesthesia, Faculty of Health Sciences, Queen's University, Kingston, ON, Canada; ${ }^{6}$ Division of Cardiology, Cardio-Oncology Program, McMaster University, Hamilton, ON, Canada; ${ }^{7}$ Division of Urology, Department of Surgery, McMaster University, Hamilton, ON, Canada; ${ }^{8}$ Sunnybrook Health Sciences Centre, and Department of Surgery (Urology), University of Toronto, Toronto, ON, Canada; ${ }^{9}$ Department of Oncology, McGill University, Montreal, QC, Canada; ${ }^{10}$ Division of Urology, Department of Surgery, CHU de Québec - Université Laval, Quebec City, QC, Canada, and Centre de recherche du CHU de Québec-Université Laval, axe Oncologie, Quebec City, QC, Canada; ${ }^{11}$ Centre Hospitalier de l'Université de Montréal - CHUM, Department of Radiation Oncology, Montreal, QC, Canada; ${ }^{12}$ Division of Urology, Department of Surgery, University of Ottawa and Ottawa Hospital Research Institute, Ottawa, ON, Canada; ${ }^{13}$ Princess Margaret Cancer Centre, University Health Network, Toronto, ON, Canada, and Department of Surgery (Urology), University of Toronto, Toronto, ON, Canada; ${ }^{14}$ Niagara Health, Niagara, ON, Canada; ${ }^{15}$ Western University, London, ON, Canada; ${ }^{16}$ Grand River Regional Cancer Centre, Kitchener, ON, Canada; ${ }^{17}$ Department of Surgery and Health Research Methods, Evidence and Impact, McMaster University, Hamilton, ON, Canada; ${ }^{18}$ Department of Cardiology, University of British Columbia, Vancouver, BC, Canada; ${ }^{19}$ The Population Health Research Institute, McMaster University and Hamilton Health Sciences, Hamilton, ON, Canada; ${ }^{20}$ Department of Health Research Methods, Evidence, and Impact, McMaster University, Hamilton, ON, Canada

Funding: This work was awarded by Prostate Cancer Canada (Grant \#CT2015-01) and is proudly funded by the Movember Foundation and a Hamilton Health Sciences Strategic Research Initiative.

Cite as: Fervaha G, Izard JP, Trip DA, et al. Psychological morbidity associated with prostate cancer: rates and predictors of depression in the RADICAL PC study. Can Urol Assoc J 2020 November 17; Epub ahead of print. http://dx.doi.org/10.5489/cuaj.6912

Published online November 17, 2020 


\begin{abstract}
Introduction: Across all cancer sites and stages, prostate cancer has one of the greatest median five-year survival rates, highlighting the important focus on survivorship issues following diagnosis and treatment. In the current study, we sought to evaluate the prevalence and predictors of depression in a large, multicenter, contemporary, prospectively collected sample of men with prostate cancer.
\end{abstract}

Methods: Data from the current study were drawn from the baseline visit of men enrolled in the RADICAL PC study. Men with a new diagnosis of prostate cancer or patients initiating androgen deprivation therapy for prostate cancer for the first time were recruited. Depressive symptoms were evaluated using the nine-item version of the Patient Health Questionnaire (PHQ-9). To evaluate factors associated with depression, a multivariable logistic regression model was constructed, including biological, psychological, and social predictor variables.

Results: Data from 2445 patients were analyzed. Of these, $201(8.2 \%)$ endorsed clinically significant depression. Younger age (odds ratio [OR] 1.38; 95\% confidence interval [CI] 1.161.60 per 10-year decrease), being a current smoker (OR 2.77; 95\% CI 1.66-4.58), former alcohol use (OR 2.63; 95\% CI 1.33-5.20), poorer performance status (OR 5.01; 95\% CI 3.49-7.20), having a pre-existing clinical diagnosis of depression or anxiety (OR 3.64; 95\% CI 2.42-5.48), and having high-risk prostate cancer (OR 1.49; 95\% CI 1.05-2.12) all conferred independent risk for depression.

Conclusions: Clinically significant depression is common in men with prostate cancer. Depression risk is associated with a host of biopsychosocial variables. Clinicians should be vigilant to screen for depression in those patients with poor social determinants of health, concomitant disability, and advanced disease. 


\section{Introduction}

Prostate cancer is characterized by long term survival, particularly in men presenting with localized disease, thus survivorship issues have become increasingly important ${ }^{1}$. Many men with a diagnosis of prostate cancer will also experience clinically relevant depression at some point during their cancer journey ${ }^{2}$. Multiple studies conducted over the last two decades have pointed toward psychological morbidity and depression in particular as an important element of survivorship $^{3,4}$.

A number of studies have been conducted to quantify the burden of depressive symptoms in men with prostate cancer. A meta-analysis of prevalence rates found that approximately 15$18 \%$ of patients experienced clinical depression, and this rate was similar across treatment phases $^{2}$. An analysis of the Surveillance, Epidemiology, and End Results-Medicare linked (SEER) database, found a prevalence rate of $20 \%$ of both depression and other mental health issues, following a prostate cancer diagnosis ${ }^{5}$. In SEER, several risk factors for psychological morbidity were identified, including age, comorbidities, treatment setting, marital status, and burden of urinary symptoms. In another study, the prevalence of depression in a cohort of prospectively recruited patients with prostate cancer was $38 \%{ }^{6}$. An important limitation of both of these studies was the ascertainment of depression, which was performed using administrative diagnostic codes and a generic health-related quality of life scale respectively. The precision of these approaches to identify depression is likely to be limited. Moreover, these data were collected over a decade ago, therefore their generalizability to contemporary patient populations is unknown.

The primary objective of the current study was to estimate the prevalence of depression in a large, contemporary, multi-center, prospective cohort of patients with prostate cancer. The secondary objective was to explore variables that are associated with an increased risk for depression in this population.

\section{Methods}

We undertook an analysis of baseline data from the Role of Androgen Deprivation Therapy in Cardiovascular Disease - A Longitudinal Prostate Cancer (RADICALPC) study, which is an ongoing, prospective cohort study that has recruited participants from 16 academic and community cancer sites in Canada ${ }^{7}$.

Men were eligible for the study if they: i) had a diagnosis of prostate cancer established within 12 months; or ii) were initiating androgen deprivation therapy (ADT) for the first time, including patients who had commenced ADT for the first time within 6 months of enrollment or would commence ADT within 1 month after enrollment. Patients were recruited between December 2015 and December 2019, with data collection ongoing. In the present article, we report baseline data from the RADICAL PC study. 


\section{Depression}

Depressive symptoms were evaluated using the 9 item version of the Patient Health Questionnaire (PHQ-9) ${ }^{8}$. Symptoms included in the PHQ-9 are based on the diagnostic criteria for Major Depressive Disorder and include depressed mood, anhedonia, insomnia, anergia, changes in appetite, guilt, cognitive dysfunction, psychomotor changes and suicidal ideation. A score of 8 or higher on this scale represents clinically significant depression ${ }^{9}$. This score has been recommended by the American Society of Clinical Oncology as representing a level of depressive symptom severity that warrants intervention ${ }^{10}$.

\section{Covariates}

Patient data collected included age, level of education, employment, living circumstances (alone or with co-habitants), ethnicity, alcohol and tobacco use, body-mass index, medical comorbidities, erectile dysfunction ${ }^{11}$, and a pre-existing diagnosis of depression or anxiety disorders. In addition, the following information was collected on the prostate cancer: stage, Gleason score and prostate cancer risk (Table 1). Prostate cancer risk was estimated using an adaptation of the approach employed by D'Amico et al. ${ }^{7,12}$. Participants with all of: 1) stage T1c or T2a disease and 2) a prostate specific antigen concentration $\leq 10 \mathrm{ng} / \mathrm{mL}$ and 3 ) a Gleason histological grade of $\leq 6$ were considered low-risk. Participants with T2c disease or a prostate specific antigen concentration $>20 \mathrm{ng} / \mathrm{mL}$ or a Gleason histological grade of $\geq 8$ or non-localized disease or biochemical relapse were considered high-risk. Participants with a prostate specific antigen concentration $>10 \mathrm{ng} / \mathrm{mL}$ and $\leq 20 \mathrm{ng} / \mathrm{mL}$ or a Gleason histological grade $3+4$ or $4+3$ or $\mathrm{T} 2 \mathrm{~b}$ disease were considered intermediate-risk.

Patient performance status, representing a global assessment of their ability to carry out their normal routine and activities of daily living, was evaluated by the Eastern Cooperative Oncology Group [ECOG] score ${ }^{13}$. The ECOG score ranges from 0 to 5 , with a score of 0 representing a fully active patient without any restrictions. A score of 4 indicates a patient that is completely disabled, cannot carry out any self-care and/or non-ambulatory for the vast majority of their days, and a score of 5 indicates death.

\section{Statistical analysis}

Statistical analysis was performed using STATA 16.0 (StataCorp, College Station, TX, USA). To evaluate predictors of depression, logistic regression models were constructed including biological, psychological, and social predictor variables. The multivariable model included exposures with a univariable $\mathrm{p}$-value $<0.1$. Erectile dysfunction was omitted from the multivariable model because $57 \%$ of the cohort were not sexually active. Also, we omitted metastatic disease and Gleason score from the multivariable model in favour of prostate cancer risk as prostate cancer risk incorporated histopathology. In the multivariable model, a p-value $<0.05$ was considered significant. 


\section{Results}

\section{Sample characteristics}

Participant characteristics are detailed in Table 1. The sample included 2445 participants, 2263 $(93 \%)$ of whom were diagnosed with prostate cancer within the previous 12 months. The mean age was 68 years, the majority of the sample was Caucasian with good performance status. Among the patients with localized disease, approximately half had high risk prostate cancer. Only $7 \%$ of patients had a documented history of metastatic disease. Eleven percent of the sample had a history of a clinical diagnosis of depression or anxiety. Notably, the median PHQ-9 score was quite low.

\section{Prevalence of depression}

Across the entire sample $201(8.2 \%)$ patients had depression. This includes $182(8.0 \%)$ of patients with a new diagnosis of prostate cancer, and $100(10.6 \%)$ men beginning treatment with androgen deprivation therapy, the latter group having a significantly higher prevalence of depression $\left(\chi^{2}=5.23, \mathrm{p}=0.02\right)$.

\section{Factors associated with depression}

Multiple variables demonstrated a univariate relationship with depression among our entire sample of men with prostate cancer (Table 2).Specifically, participants with depression had lower levels of education than those without depression. Participants with depression were more likely to have multiple medical co-morbidities, be smokers or be former alcohol users. Participants with depression were also more likely to have poorer performance status scores, with approximately $43 \%$ of participants demonstrating some degree of loss of functional independence, whereas only $12 \%$ of participants without depression exhibited loss of functional independence. Of the entire sample, $43 \%$ of the sample was sexually active, and among these participants, those with depression reported significantly worse erectile function. Participants who were depressed were more likely to have high risk prostate cancer. However, participants with depression were no more likely to have metastatic disease. Unsurprisingly, participants with depression were more likely to have had a pre-existing clinical diagnosis of depression and/or anxiety.

In our sensitivity analyses re-examining univariate associations, the $95 \%$ confidence intervals of all odds ratios overlapped for both sets of estimates (Supplemental table 1), suggesting similar estimates across sub-samples.

In the multivariable model, younger age, current smoking, former alcohol use, poorer performance status, high risk prostate cancer and a pre-existing diagnosis of anxiety or depression were independently associated with the presence of depression (Table 2; Figure 1). For each 10-year decrease in age, the odds of having depression increased by $38 \%$. Current smoking and former alcohol use were both associated with a near three-fold increase in the odds of depression. An inability to perform work activities was associated with a five-fold increase in 
the odds of depression, while high prostate cancer risk was associated with a $49 \%$ increase in the odds of depression. As expected, a history of anxiety or depression was associated with a nearly four-fold increase in the odds of exhibiting depression.

\section{Discussion}

The major findings from this large, contemporary, prospective, representative study of men with prostate cancer were: i) 1 in 12 endorsed clinically relevant depression; ii) the characteristics most strongly associated with the presence of depression were younger age, smoking, former alcohol use, poorer performance status, high prostate cancer risk and a history of depression or anxiety .

One of the aims of this study was to provide a contemporary estimate of the prevalence of depression rates in a prospectively collected multi-centre sample of men with prostate cancer. We report a rate of $8.2 \%$ of men with prostate cancer endorsing clinically significant depression. This prevalence rate is notably lower than many previously published estimates. One of the seminal papers to summarize prevalence rates in this population quotes a depression rate of 15 $18 \%{ }^{2}$. Another study similarly cites a fairly high rate between $20-38 \%{ }^{6}$. Many factors may contribute to the relatively lower rate observed in the current study, including differences in measurement tool to assess depression and characteristics of patients recruited. Another difference between these previous studies and the current investigation is the recruitment of patients in the last few years versus those collected decades ago, which may reflect differences in care pathways across time and advances in treatment. Consistent with this hypothesis, our estimate is similar to a recent large population-based survey study that employed a single item to quantify burden of depression ${ }^{14}$.

Given the many adverse effects associated with depression, any prevalence rate of men with prostate cancer burdened by this psychological morbidity deserves consideration. This is consistent with recommendations to assess for depression among prostate cancer survivors ${ }^{15}$. It is unclear as to how this rate of depression among men with prostate cancer might compare to men without malignant disease. We are not aware of any well-controlled studies with appropriate comparison subjects that provide data to answer this question. There are several estimates of depression in the general population. Two studies on the point prevalence of depression among men in Canada cited rates less than $2 \%{ }^{16,17}$. This is consistent with an estimate from a systematic review of studies on community samples of people aged 55 and above, which also demonstrated a prevalence rate for major depression of less than $2 \%{ }^{18}$. Thus, the depression rates observed in our analysis suggest that men with prostate cancer have a relatively high rate of depression. Notably, a recent Canadian survey study found increase rates of depression among men with prostate cancer when compared to those without any oncologic history ${ }^{19}$.

An American Society of Clinical Oncology (ASCO) guideline for the assessment of depression among adults with cancer identifies several variables to consider when evaluating risk for depression ${ }^{10}$. Specifically, prior depression or other mental health issues, family history, 
advanced disease, presence of comorbidities, absence of a partner and lower socioeconomic status are recommended as key risk factors to consider in assessments. It is worth noting that this guideline did not cite any specific evidence base for selected specific risk factors, and it is unclear whether these risk factors differ for different malignances. More specific to prostate cancer, the American Cancer Society has published survivorship care guidelines suggesting the following as key risk factors: unmarried, low educational level, advanced disease, low physical or cognitive functioning, younger age, multiple medical comorbidities, presence of psychiatric history and poor coping skills ${ }^{20}$. These risk factors were identified from a study of 339 men with prostate cancer ${ }^{21}$. Our results are positioned to inform these recommendations. Specifically, our findings underscore the importance of overall functional status and higher risk disease as variables to consider in the evaluation of risk for depression. Prior history of mental health issues, employment status and age were also found to modify the odds of having depression in both the current study and prior investigations ${ }^{5,6}$. Smoking status is not a variable considered in many investigations, and was not mentioned in the aforementioned guidelines; however, our results highlight this variable as also having significance when evaluating for depression. The mechanism underlying this is unclear, but we speculate the link may relate to socioeconomic status $^{22}$.

Both of the aforementioned guidelines note advanced disease as a risk factor for depression among men with prostate cancer ${ }^{10,20}$. Our results are in keeping with this statement. In our multivariable analysis, men with high risk prostate cancer were at a $49 \%$ increased risk of having depression compared to men with low or intermediate risk prostate cancer. Interestingly, in our univariable analysis, those with metastatic disease were not at an increased risk of depression compared to those with localized disease. Findings from previous studies are inconsistent, with some finding no relationship between indicators of advanced disease and depression $^{5,6}$, and others reporting an association ${ }^{14}$. This relationship between advanced disease and depression may in part be related to use of $\mathrm{ADT}^{22}$. In our sample, men who were initiating ADT for the first time had a higher prevalence of depression than men for whom there was no plan to initiate ADT. Notably, this sub-sample of patients included participants who had recently started ADT as well as those patients who are not on ADT but planned to initiate. The relationship between prostate cancer risk, ADT use and psychological outcomes is perhaps best disentangled using a longitudinal study design.

Poor performance status had the strongest association with depression among men with prostate cancer in our multivariable model. Performance status scores are a global assessment for functional status and capacity. Many factors can theoretically lead to functional loss including physical, physiologic and psychological causes. Poor performance status has been identified as a predictor for depression in patients with non-prostate malignancies including lung ${ }^{23}$ and ovarian cancer ${ }^{24}$.There is also a literature linking physical disability and depression in non-cancer patients $^{25-27}$; however, the mechanisms underlying this relationship is not well understood. 
Among men with prostate cancer, it may be the case that functional limitations directly predispose to depression. We speculate that this relationship is better conceptualized as indirect, through variables not examined in our study. Such variables could include social support or lack thereof, catastrophizing cognitions, and/or other such factors. Another possibility is the presence of a third variable that is indirectly associated with both performance status and depression, such as pain. It should be underscored that these are speculations, and the mechanisms linking performance status and depression have yet to be elucidated.

While the current investigation has several strengths, some limitation warrant mention. Our prediction model included several biopsychosocial variables hypothesized to have an association with depression; nonetheless, our model falls short of being comprehensive. Variables such as urinary function or specific psychological variables were not available. Our current investigation was designed to evaluate the point prevalence of depression in men with prostate cancer. Given the cross-sectional study design, we cannot distinguish incident from chronic cases of depression. A prospective study would be ideally suited to assess for incident depression. As we continue to follow this large prospective cohort of prostate cancer patients as part of the RADICAL PC trial, we will continue to assess mental health at regular intervals. It is the goal of future analyses to provide answers as to rates of incident depression and long-term variations in depression scores over time.

\section{Conclusions}

Our study examined the prevalence and predictors of depression in a large, contemporary, prospectively collected sample of men with prostate cancer. In this sample, we report an overall point prevalence of depression of $8 \%$. This is lower than many previously quoted prevalence rates, but still elevated relative to general population estimates. Our multivariable model also identified several variables as significantly associated with the risk for depression in this sample, chiefly performance status. These results should help clinicians in the screening and assessment of depression in patients with prostate cancer. 


\section{References}

1. Miller KD, Siegel RL, Lin CC et al.: Cancer treatment and survivorship statistics, 2016. CA Cancer J Clin 2016; 66:271-89

2. Watts S, Leydon G, Birch B et al.: Depression and anxiety in prostate cancer: a systematic review and meta-analysis of prevalence rates. BMJ Open 2014; 4:e003901

3. Fervaha G, Izard JP, Tripp DA et al.: Depression and prostate cancer: A focused review for the clinician. Urologic oncology 2019; 37:382-288

4. Christie DR, Sharpley CF: Prostate cancer: Depression and prostate cancer--why do they show up together? Nat Rev Urol 2014; 11:547-8

5. Ravi P, Karakiewicz PI, Roghmann F et al.: Mental health outcomes in elderly men with prostate cancer. Urol Oncol 2014; 32:1333-40

6. Erim DO, Bensen JT, Mohler JL et al.: Prevalence and predictors of probable depression in prostate cancer survivors. Cancer 2019; 125:3418-27

7. Leong DP, Fradet V, Shayegan B et al.: Cardiovascular Risk in Men with Prostate Cancer: Insights from the RADICAL PC Study. Journal of Urology 2020:10.1097/JU. 0000000000000714

8. Kroenke K, Spitzer RL, Williams JB: The PHQ-9: validity of a brief depression severity measure. J Gen Intern Med 2001; 16:606-13

9. Manea L, Gilbody S, McMillan D: Optimal cut-off score for diagnosing depression with the Patient Health Questionnaire (PHQ-9): a meta-analysis. CMAJ 2012; 184:E191-6

10. Andersen BL, DeRubeis RJ, Berman BS et al.: Screening, assessment, and care of anxiety and depressive symptoms in adults with cancer: an American Society of Clinical Oncology guideline adaptation. J Clin Oncol 2014; 32:1605-19

11. Rosen RC, Cappelleri JC, Smith MD et al.: Development and evaluation of an abridged, 5-item version of the International Index of Erectile Function (IIEF-5) as a diagnostic tool for erectile dysfunction. Int J Impot Res 1999; 11:319-26

12. D'Amico AV, Whittington R, Malkowicz SB et al.: Biochemical outcome after radical prostatectomy, external beam radiation therapy, or interstitial radiation therapy for clinically localized prostate cancer. JAMA 1998; 280:969-74

13. Oken MM, Creech RH, Tormey DC et al.: Toxicity and response criteria of the Eastern Cooperative Oncology Group. Am J Clin Oncol 1982; 5:649-55

14. Downing A, Wright P, Hounsome L et al.: Quality of life in men living with advanced and localised prostate cancer in the UK: a population-based study. Lancet Oncol 2019; 20:436-47

15. Resnick MJ, Lacchetti C, Bergman J et al.: Prostate cancer survivorship care guideline: American Society of Clinical Oncology Clinical Practice Guideline endorsement. J Clin Oncol 2015; 33:1078-85

16. Patten SB, Wang JL, Williams JV et al.: Descriptive epidemiology of major depression in Canada. Can J Psychiatry 2006; 51:84-90

17. Akhtar-Danesh N, Landeen J: Relation between depression and sociodemographic factors. Int J Ment Health Syst 2007; 1:4 
18. Beekman AT, Copeland JR, Prince MJ: Review of community prevalence of depression in later life. Br J Psychiatry 1999; 174:307-11

19. Ilie G, Rutledge R, Sweeney E: Anxiety and depression symptoms in adult males in Atlantic Canada with or without a lifetime history of prostate cancer. Psychooncology 2020; 29:280-6

20. Skolarus TA, Wolf AM, Erb NL et al.: American Cancer Society prostate cancer survivorship care guidelines. CA Cancer J Clin 2014; 64:225-49

21. Nelson CJ, Mulhall JP, Roth AJ: The association between erectile dysfunction and depressive symptoms in men treated for prostate cancer. J Sex Med 2011; 8:560-6

22. Hiscock R, Bauld L, Amos A et al.: Socioeconomic status and smoking: a review. Ann $N$ Y Acad Sci 2012; 1248:107-23

23. Cella DF, Orofiamma B, Holland JC et al.: The relationship of psychological distress, extent of disease, and performance status in patients with lung cancer. Cancer 1987; 60:1661-7

24. Bodurka-Bevers D, Basen-Engquist K, Carmack CL et al.: Depression, anxiety, and quality of life in patients with epithelial ovarian cancer. Gynecol Oncol 2000; 78:302-8

25. Turner RJ, Noh S: Physical disability and depression: a longitudinal analysis. J Health Soc Behav 1988; 29:23-37

26. Teychenne M, Ball K, Salmon J: Physical activity and likelihood of depression in adults: a review. Prev Med 2008; 46:397-411

27. Zhai L, Zhang Y, Zhang D: Sedentary behaviour and the risk of depression: a metaanalysis. Br J Sports Med 2015; 49:705-9 


\section{Figures and Tables}

Fig. 1. Forest plot depicting the adjusted odds ratios for the relationship between depression and various predictor variables. BMI: body mass index; ECOG: Eastern Cooperative Oncology Group Performance Status Score; MM: multi-morbidity; PC: prostate cancer.

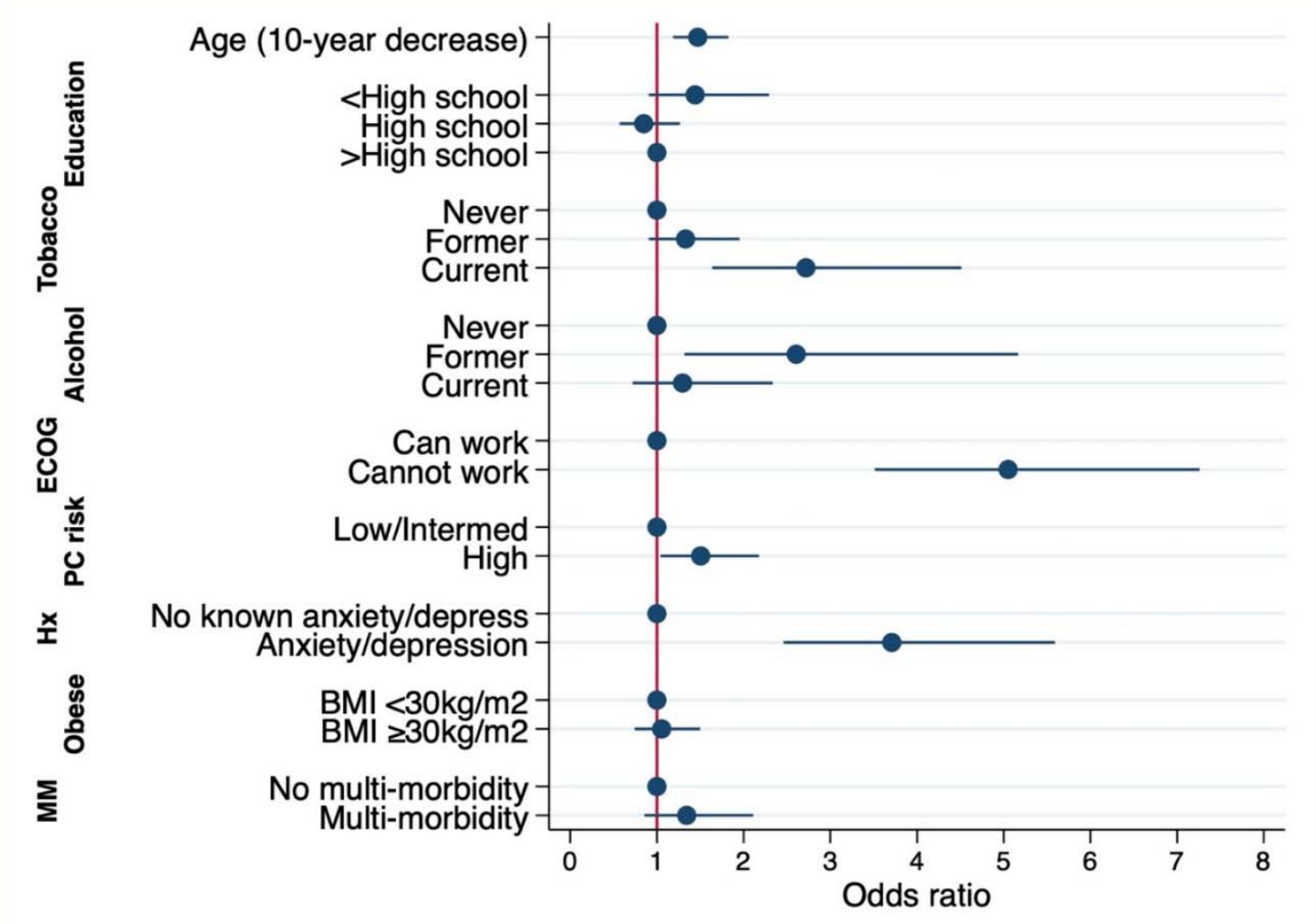




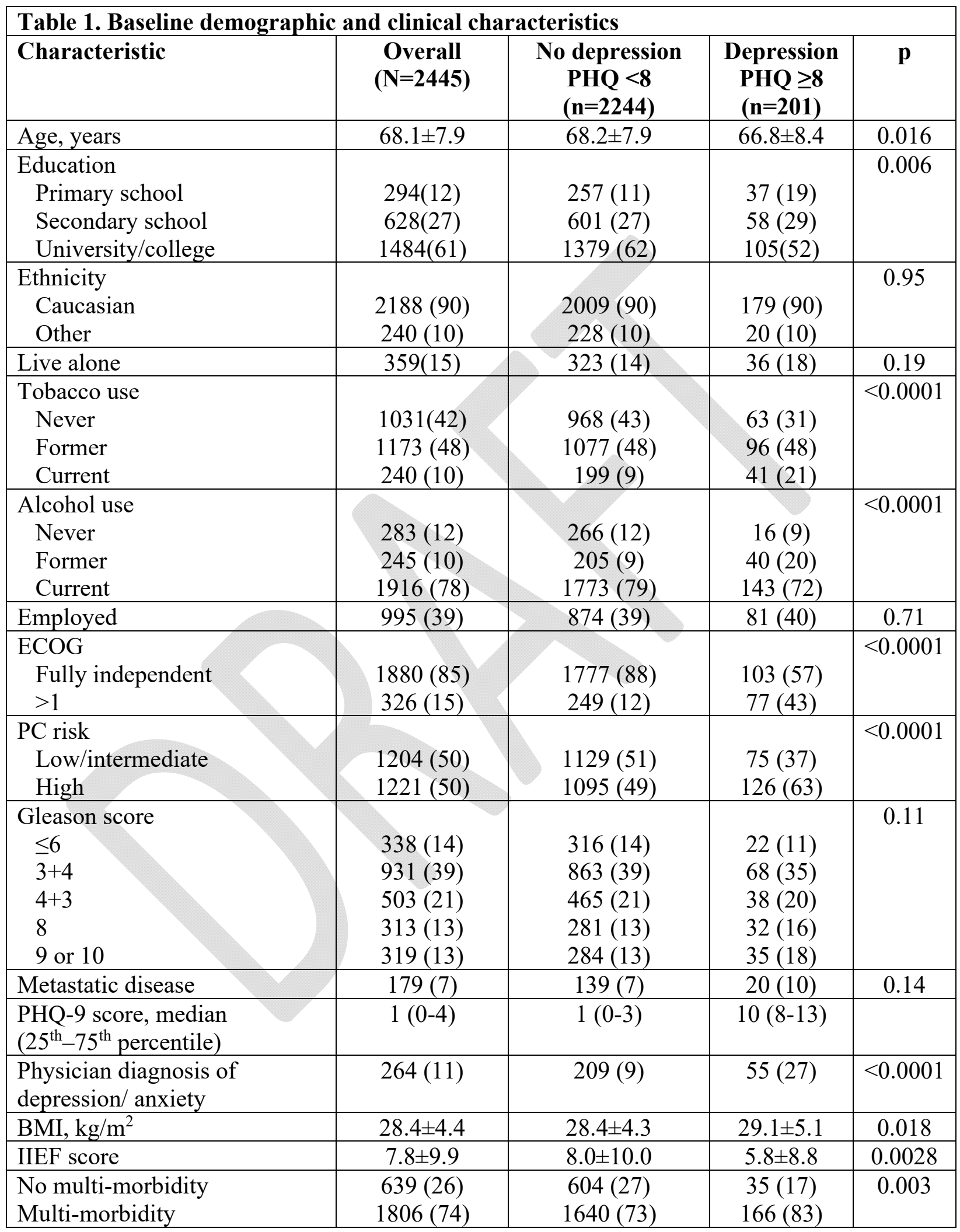


ADT: androgen deprivation therapy; BMI: body mass index; ECOG: Eastern Cooperative Oncology Group Performance Status Score; IIEF: International Index of Erectile Function; PC: prostate cancer; PHQ-9: Patient Health Questionnaire.

\begin{tabular}{|c|c|c|c|c|c|c|}
\hline \multirow[t]{2}{*}{ Predictor variable } & \multicolumn{3}{|c|}{ Univariable models } & \multicolumn{3}{|c|}{ Multivariable model } \\
\hline & OR & $95 \% \mathrm{CI}$ & $\mathbf{p}$ & OR & $95 \% \mathrm{CI}$ & $\mathbf{p}$ \\
\hline $\begin{array}{l}\text { Age (per 10-year } \\
\text { decrease) }\end{array}$ & 1.23 & $1.04-1.42$ & 0.016 & 1.38 & $1.16-1.60$ & 0.001 \\
\hline \multicolumn{7}{|l|}{ Education } \\
\hline$>$ Secondary school & 1 & & & 1 & & \\
\hline Secondary school & 1.27 & $0.91-1.77$ & 0.17 & 0.84 & $0.56-1.26$ & 0.40 \\
\hline Primary school & 1.89 & $1.27-2.81$ & 0.002 & 1.42 & $0.89-2.26$ & 0.14 \\
\hline \multicolumn{7}{|l|}{ Tobacco use } \\
\hline Never & 1 & & & 1 & & \\
\hline Former & 1.37 & $0.99-1.90$ & 0.061 & 1.34 & $0.91-1.96$ & 0.14 \\
\hline Current & 3.17 & $2.08-4.83$ & $<0.0001$ & 2.77 & $1.66-4.58$ & $<0.0001$ \\
\hline \multicolumn{7}{|l|}{ Alcohol } \\
\hline Never & 1 & & & 1 & & \\
\hline Former & 3.05 & $1.68-5.54$ & $<0.0001$ & 2.63 & $1.33-5.20$ & 0.006 \\
\hline Current & 1.26 & $0.75-2.12$ & 0.38 & 1.30 & $0.72-2.34$ & 0.38 \\
\hline Employed & 1.06 & $0.79-1.42$ & 0.71 & - & - & - \\
\hline $\begin{array}{l}\text { Poor performance } \\
\text { status }(E C O G>1)\end{array}$ & 5.34 & $3.86-7.37$ & $<0.0001$ & 5.01 & $3.49-7.20$ & $<0.0001$ \\
\hline $\begin{array}{l}\text { PC risk } \\
\text { Low/intermediate } \\
\text { High } \\
\end{array}$ & $\begin{array}{c}1 \\
1.73 \\
\end{array}$ & $1.29-2.33$ & $<0.0001$ & $\begin{array}{c}1 \\
1.49 \\
\end{array}$ & $1.05-2.12$ & 0.027 \\
\hline $\begin{array}{l}\text { Gleason } 3+4 \text { or } \\
\text { higher }\end{array}$ & 1.34 & $1.00-1.79$ & 0.054 & - & - & - \\
\hline Metastatic disease & 1.45 & $0.89-2.36$ & 0.14 & - & - & - \\
\hline $\begin{array}{l}\text { Pre-existing } \\
\text { diagnosis of }\end{array}$ & 3.67 & $2.61-5.16$ & $<0.0001$ & 3.64 & $2.42-5.48$ & $<0.0001$ \\
\hline
\end{tabular}




\begin{tabular}{|l|c|c|c|c|c|c|}
\hline $\begin{array}{l}\text { depression or } \\
\text { anxiety }\end{array}$ & & & & & & \\
\hline $\begin{array}{l}\text { BMI } \\
<30 \mathrm{~kg} / \mathrm{m}^{2} \\
\geq 30 \mathrm{~kg} / \mathrm{m}^{2}\end{array}$ & $\begin{array}{c}1 \\
1.34\end{array}$ & $0.99-1.82$ & 0.055 & 1.07 & $0.75-1.51$ & 0.72 \\
\hline $\begin{array}{l}\text { Erectile dysfunction } \\
\text { (IIEF score }<22 \text { ) }\end{array}$ & 1.53 & $0.91-2.57$ & 0.11 & - & - & - \\
\hline Multi-morbidity & 1.75 & $1.20-2.54$ & 0.004 & 1.35 & $0.86-2.12$ & 0.19 \\
\hline
\end{tabular}

BMI: body mass index; CI: confidence interval; ECOG: Eastern Cooperative Oncology Group Performance Status Score; IIEF: International Index of Erectile Function; OR: odds ratio; PC: prostate cancer. 


\begin{tabular}{|c|c|c|c|c|}
\hline \multicolumn{5}{|c|}{$\begin{array}{l}\text { Supplementary Table 1. Univariate associations between selected variables and } \\
\text { depression across the full sample }\end{array}$} \\
\hline \multirow[t]{2}{*}{ Predictor variable } & \multicolumn{2}{|c|}{ New diagnosis } & \multicolumn{2}{|c|}{ To start ADT } \\
\hline & OR & p & OR & p \\
\hline $\begin{array}{l}\text { Age (10-year } \\
\text { decrease) }\end{array}$ & $1.20(1.00-1.40)$ & 0.047 & $1.31(1.05-1.58)$ & 0.018 \\
\hline \multicolumn{5}{|l|}{ Education } \\
\hline Primary school & $1.65(1.07-2.54)$ & 0.023 & $1.64(0.96-2.83)$ & 0.073 \\
\hline Secondary school & $1.18(0.83-1.68)$ & 0.35 & $1.06(0.65-1.74)$ & 0.82 \\
\hline$>$ Secondary school & Ref & & Ref & \\
\hline \multicolumn{5}{|l|}{ Tobacco use } \\
\hline Never & Ref & & Ref & \\
\hline Current & $3.13(2.02-4.84)$ & $<0.001$ & $2.81(1.50-5.24)$ & 0.001 \\
\hline Former & $1.30(0.92-1.83)$ & 0.14 & $1.27(0.79-2.03)$ & $0.33 \mathrm{~s}$ \\
\hline \multicolumn{5}{|l|}{ Alcohol } \\
\hline Never & Ref & & Ref & \\
\hline Current & $1.20(0.70-2.05)$ & 0.51 & $1.32(0.62-2.83)$ & 0.47 \\
\hline Former & $3.24(1.76-5.98)$ & $<0.0001$ & $2.19(0.62-2.83)$ & 0.078 \\
\hline Employed & $1.01(0.74-1.38)$ & 0.94 & $0.95(0.60-1.49)$ & 0.81 \\
\hline $\begin{array}{l}\text { Poor performance } \\
\text { status }(\mathrm{ECOG}>1)\end{array}$ & $5.48(3.91-7.70)$ & $<0.001$ & $5.35(3.40-8.44)$ & $<0.0001$ \\
\hline \multicolumn{5}{|l|}{ Gleason score } \\
\hline 6 or $3+4$ & Ref & 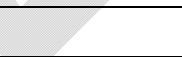 & Ref & \\
\hline $4+3$ or higher & $1.38(1.01-1.88)$ & 0.041 & $0.87(0.52-1.46)$ & 0.61 \\
\hline Metastatic disease & $1.56(0.93-2.61)$ & 0.094 & $1.14(0.68-1.92)$ & 0.63 \\
\hline $\begin{array}{l}\text { Pre-existing history of } \\
\text { depression or anxiety }\end{array}$ & $3.64(2.55-5.21)$ & $<0.0001$ & $3.89(2.34-6.47)$ & $<0.0001$ \\
\hline $\mathrm{BMI} \geq 30 \mathrm{~kg} / \mathrm{m}^{2}$ & $1.41(0.92-2.16)$ & 0.12 & $1.32(0.96-1.81)$ & 0.090 \\
\hline $\begin{array}{l}\text { Erectile dysfunction } \\
\text { (IIEF score }>22 \text { ) }\end{array}$ & $1.45(0.86-2.45)$ & 0.17 & $2.19(0.62-7.73)$ & 0.22 \\
\hline $\begin{array}{l}\text { Multiple medical } \\
\text { comorbidities }\end{array}$ & $1.90(1.27-2.84)$ & 0.002 & $1.30(0.77-2.20)$ & 0.32 \\
\hline
\end{tabular}

ADT: androgen deprivation therapy; BMI: body mass index; ECOG: Eastern Cooperative Oncology Group Performance Status Score; IIEF: International Index of Erectile Function; OR: odds ratio; PC: prostate cancer.

\section{Disclosures}

Dr. Taussky has received research support from Sanofi. Dr. Gopaul has served on advisory boards for Bayer and Tersera and has received honoraria from Astra Zeneca. 